\title{
Lean Leadership in production ramp-up
}

\author{
Uwe Dombrowski ${ }^{1}$, Jonas Wullbrandt ${ }^{1 *}$ \\ ${ }^{1}$ Institute for Advanced Industrial Management (IFU) \\ Technische Universität Braunschweig, Langer Kamp 19, 38106 Braunschweig, Germany \\ *Corresponding author. Tel: +49 531391 2704, E-mail: j.wullbrandt@tu-bs.de
}

\begin{abstract}
Today's production systems are complex sociotechnical systems. Especially during the production system ramp-up phase, which is of particular importance in terms of ensuring a timely, qualitatively and cost efficient market entry, both technical challenges, as well as the integration of human employees with their diverse abilities, wants, and needs, must be considered. Due to a growing number of product variants, shorter lead times, and global supply chains, planning and launching production systems can be seen as a competitive advantage. Consequently, managing the period of production system ramp-up, which is characterized by high production demand but low production control, becomes increasingly important. To handle the increasing complexity and uncertainty in this special phase, human decision makers must be adequately supported by an appropriate leadership style. In this paper, the Lean Leadership approach will be identified to best meet the special requirements of the socio-technical production system ramp-up phase. The results of a mixed-methods data collection, which has been conducted in commercial vehicle industry, help to better manage complex product launches in the future.
\end{abstract}

Keywords: Production system, Ramp-up, Leadership

\section{Introduction}

In times of rising customer requirements and increasing globalization, products as well as the associated production systems need to be adjusted or redesigned in increasingly shorter time periods. This is necessary in order to ensure the timely market rollout of the new products. Consequently, the cost-efficient, high-quality and timely management of production system ramp-ups becomes a competitive advantage for organizations in the future. A production system can be described as a complex socio-technical system in which human, organizational as well as technical aspects need to be coordinated in order to create value. [1] A production system ramp-up, in turn, can be seen as the phase in which the complex socio-technical system needs to be transferred from an uncertain and instable state into a stable series production state. [2][3]

Taking into consideration that each production ramp-up phase is unique, has a defined beginning as well as a defined end point and is measured by its degree of fulfillment of certain objectives, such as quality, time or costs, it can be regarded as a project. The 
following definition in the DIN 69900-5:2009 says that a project is an "initiative that is characterized by the uniqueness of its conditions as a whole"[4]. Given that a production ramp-up can be described as a project, ramp-up management, in turn, can be compared with project management. Regarding DIN norm 69901-5:2009 project management is defined as "all leadership tasks, -organization, -techniques, and -means that are necessary for the initiation, definition, planning, steering and completion of projects." [5] Consequently, it can be derived that the role of leadership is of special importance for managing unstable and uncertain production system ramp-up phase.

\section{Production system ramp-up - a socio-technical perspective}

In general, production ramp-up can be described as the link between product development phase and the series fabrication process. It represents an important integral function when it comes to the physical implementation of a products' value-added processes in the overall product development process [6]. As shown in Fig. 1., the ramp-up phase builds upon the development phase, which includes the product development as well as the development of the processes and the production system.

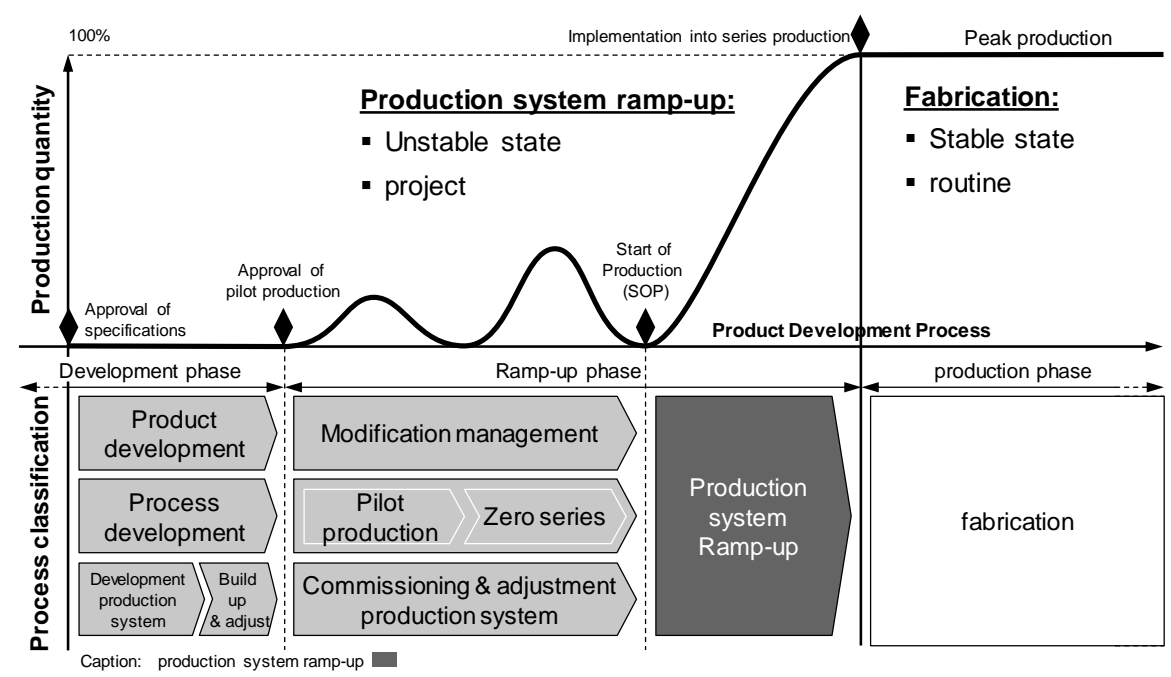

Fig. 1. Process organization of production ramp-up, based on [6][7][8][9]

Within the ramp-up phase focus is on the coordination of objects and functions in order to successfully complete the pilot production phase, the zero series production phase, the phase of commissioning and adjustment of the production system as well as the modification management phase. After fitting and setting up all product-, process- and organization-specific requirements, start of production (SOP) follows [10]. In the subsequent production system ramp-up phase, production quantity is raised. Two conflicting factors are characteristic of this period: low production capacity, and high demand. High demand arises because the product is still relatively new and might even be the 
first of its type. Thus, customers are ready to pay a premium price. However, output is low due to low production rates and unforeseen disturbances. The production process is still instable and socio-technical systems interactions are poorly understood [11]. Machine break downs are unexplainable, humans do not have practical knowledge, special operations are needed to correct product and process oversights, and other factors impede output. Over a certain time, the organization has to learn about the production processes and equipment so that yields and capacity utilization increase [12]. In case that the required production quantity is reached the production system ramp-up phase is finished and series production phase begins (compare "peak production" in Fig. 1). The aforementioned explanations show that the production system ramp-up phase is of special importance for the whole product development process since it is the first time that the complex socio-technical production system needs to perform under pressure [13]. All possible failures from previous process steps, such as the product and process development phase, that could not be anticipated or identified in the planning process will come to light and result in costly delays of the time-to-market span (compare Fig. 1). [9]
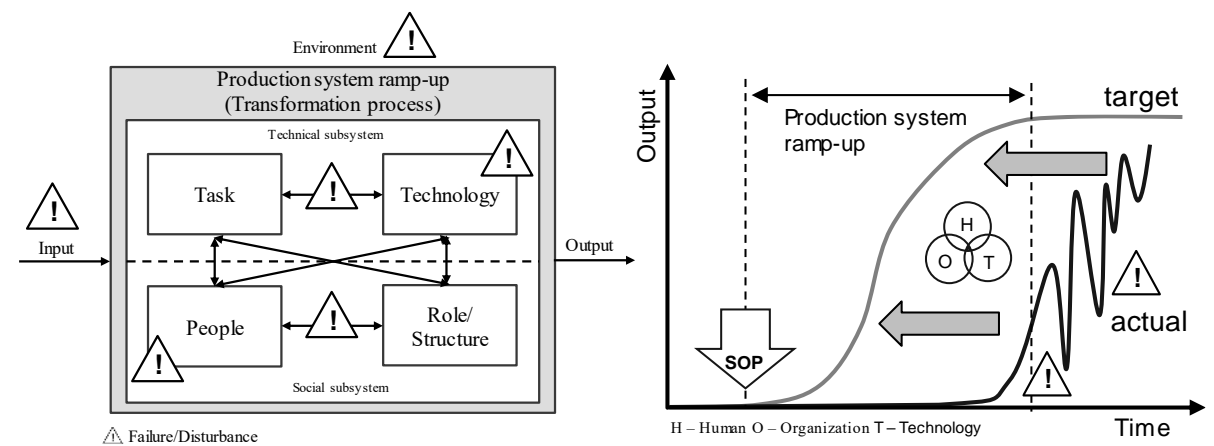

Fig. 2. Instability in socio-technical production system ramp-up, based on [14]

According to WIENDAHL [6], the production system ramp-up phase can be defined as follows: "In production system ramp-up phase, all system elements in the production system will be brought to full capacity under consideration of nominal, personnel, organizational and technical conditions. Therefore, optimization and stabilization of operational performance in terms of human oriented, organizational and technical inadequacies necessarily need be done in this special phase." It becomes clear that, once implemented, the technical subsystem is rather rigid and inflexible. Therefore, in terms of joint optimization and appropriate reaction in case of unforeseen disturbances, the social subsystem with its human elements plays a vital role in production ramp-up management [15] All ramp-up involved personnel must be guided appropriately in order to be resilient towards disturbances by developing abilities that enable to anticipate, monitor, react and learn from failures within the production system. 


\section{$3 \quad$ Lean Leadership - Principles and its application}

Whereas technical elements, such as machines or processes, can be reconfigured and reorganized easily, the reorganization of people and the creation of value-adding mindsets is nontrivial. Therefore, in context of series production in lean production systems, a people-oriented leadership style has evolved to state of the art. Several authors acknowledge that the Lean Leadership (LL) style is the important aspect in implementing and supporting a culture that focuses on value-adding, customer orientation and continuous self-development. [16] According to VDI guideline 2871, LL is defined as a "company specific, methodically set of rules and methods for goal-oriented leadership in order to sustainably implement and continuously improve a lean production system." [17] The basic design principles of lean leadership as well as their application are listed in Fig. 3.

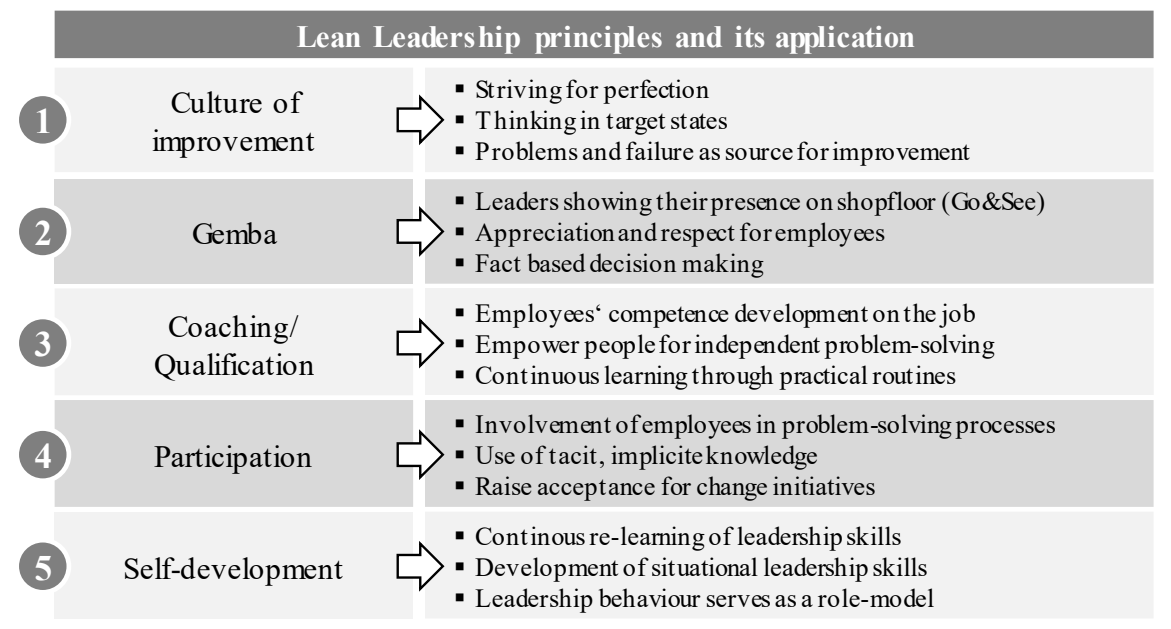

Fig. 3. Lean Leadership: Principles and its application (acc. to [17])

Similar to the general structure of lean production systems, LL orientates towards goals, processes, design principles, methods and tools [17]. As an example, LL can help to improve the KPI "product quality" by focusing on the principle "coaching”. Special guidelines help Lean leaders encourage people to build competences on the job or empower employees to solve problems independently (compare [17]). As a result, LL helps to set up a culture of continuous improvement and enables people in complex socio-technical systems to become problem solvers and decision makers in order to improve processes decentralized, independently and on a daily basis. Since implementing Lean and LL is time-consuming, the initiatives often only start up subsequently to the ramp-up project when fire-fighting is over and stable state of production has been reached. However, as DOMBROWSKI [7] has shown with the "Lean Ramp-up" approach, the application of certain Lean tools and methods can be also very beneficial in the instable production system ramp-up phase. Regarding the Lean Leadership principles and its application areas in the context of special characteristics of the production 
system ramp-up phase, it becomes obvious that a similar leadership approach might also be beneficial in terms of reducing the time-to-market span by jointly optimizing social and technical subsystem.

\section{$4 \quad$ Lean Leadership in production system ramp-up}

\subsection{Research design}

To answer the research question, whether the application of Lean Leadership might have potential for the production system ramp-up phase, a mixed-method data collection approach was conducted in a components facility of a big German commercial vehicle manufacturer [18]. First, a short self-administered questionnaire was designed including the question whether the five Lean Leadership principles, all 15 associated sub-elements as well as the ten guidelines presented in VDI guideline 2871 have 5 - much more, 4-more, 3-as much as, 2 - less, 1 - much less potential in production ramp-up phase compared to series production phase (compare 5-point Likert-type scale in Fig. 4). Since Lean Leadership has shown it applicability in series production in various industries and is equally important throughout the whole production system lifecycle, the questionnaire did not aim at investigating whether the principles are more or less important in any of the phases. Instead, the investigations shall rather give notice that some of the principles have even higher potential to cope with special characteristics of the phases, such as higher uncertainty in the instable production ramp-up phase. To control the bias in the quantitative data collection, the participants were chosen from a broad range of disciplines and professional background. Thus, the results shown in section 4.2 represent the opinion of representatives of operational and other ramp-up involved business segments, such as blue collar workers, managers of operational segments, higher managers being decision-makers in ramp-up projects, other personnel involved in ramp-up projects and people that are currently not involved in ramp-up projects. While selecting the participants it was ensured that he/she is able to draw on experience in working in production ramp-up phase as well as series production phase, in order to get an experience-based answer from the participants. The total sample size that completed the survey is $n=58$ whereby all groups of participants were approximately evenly distributed. Additionally, in order to explain the purpose of the study and to gain further in-depth understandings, a qualitative semi-structured interview was conducted with each participant before and after filling out the questionnaire. The purpose was to deepen the participants' understanding on the different characteristics of the series production phase and the production ramp-up phase as well as the LL principles and guidelines in order to ensure that they can objectively assess the potential on the Likert-type scale. At the end of the mixed-method data collection approach the participants were asked to assess the suitability of the existing LL approach for the production system ramp-up phase. On another 5-point Likert-type scale they had to estimate whether the LL approach needs to be adapted to the special characteristics of the production system ramp-up phase (5 - fully agree, 4 - agree, 3 - do not know, 2 disagree, 1 - fully disagree). 


\subsection{Results}

The survey results are illustrated in Fig. 4. The bar chart on the left hand side shows the potential of Lean Leadership principles and guidelines in production system rampup phase relatively to series production phase. For each of the five principles the arithmetic means have been calculated from the estimates of $n=58$ participants. In general, from the data analysis it can be derived that there is clear evidence that the application of the principles has high potential for production system ramp-up phase (all mean values $\overline{\mathrm{x}}_{1-5}>3,8$ ). In particular, Coaching/Qualification and Participation with a mean value $\bar{x}>4.0$ were identified to be very beneficial for the production system ramp-up phase. Especially the sub-elements "Employees' competence development on the job" $(\overline{\mathrm{x}}=4.50)$, "Striving for perfection" $(\overline{\mathrm{x}}=4.28)$ as well as "Involvement of employees in problem-solving processes" $(\overline{\mathrm{x}}=4.22)$ were considered to have very high potential in production system ramp-up phase. The results of the other 13 sub-elements of the principles are not part of this publication.

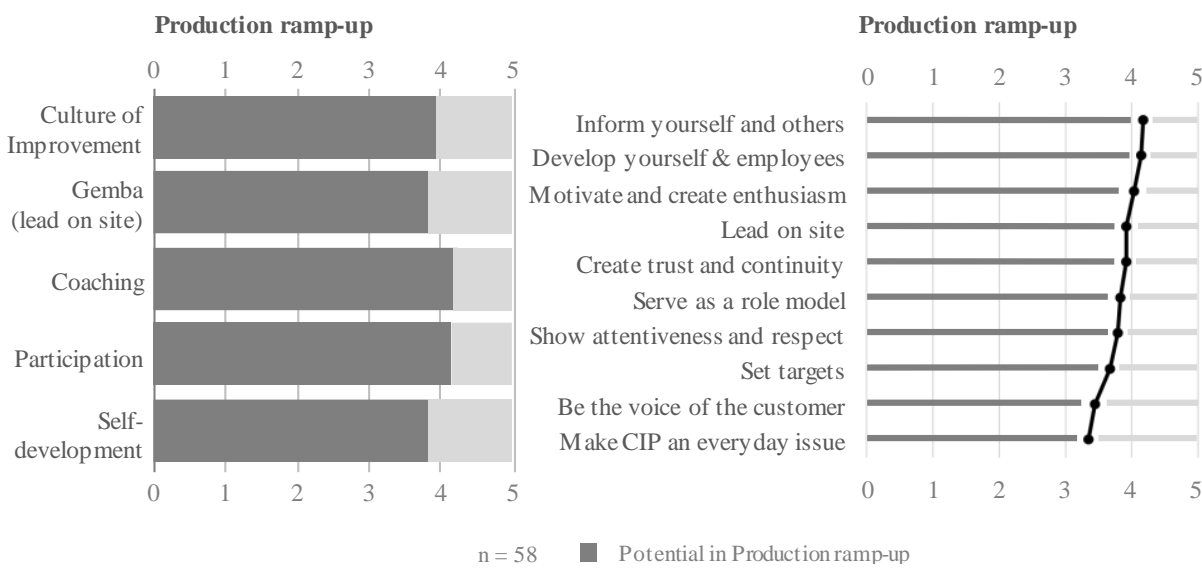

Fig. 4. Potential of Lean Leadership principles \& guidelines in production ramp-up phase

In order to identify applicable recommendations that can be helpful for better managing sociotechnical system ramp-up, the survey participants were also asked to assess the potential of applying the Lean Leadership guidelines in production system ramp-up relatively to series production on the 5-point Likert-type scale. The results can be seen on the right hand side in Fig. 4. Especially the leadership tasks "Inform yourself and others" ( $\overline{\mathrm{x}}=4.17)$ and "Develop yourself and your employees" $(\overline{\mathrm{x}}=4.14)$ were identified to have high potential in the production ramp-up phase. With an average mean value of $\bar{x}_{1-10}=3,83$ all recommendations should be especially focused in ramp-up projects in order to optimize the instable sociotechnical system. Therefore, in their descending order the presented guidelines should serve as a basis for the development of a ramp-up specific LL orientation that focuses on transparency, employee development, problem-solving and participative value creation. The need for adapting the existing LL approach by prioritizing certain principles and guidelines was also emphasized by the survey participants. With a mean value $\bar{x}=4.07$ the 58 respondents agree that the LL 
approach needs to be adapted to the special requirements of the production system ramp-up phase.

\section{Conclusion}

Since it is the first-time interaction of the planned technical subsystem and the social subsystem, the production system ramp-up phase can be characterized by its high complexity and uncertainty. In order to ensure a timely, qualitatively and cost efficient market entry, both technical challenges, as well as the integration of human employees with their diverse abilities, wants, and needs, must be considered in a ramp-up project. Consequently, decision makers in production ramp-up phase must be adequately supported by an appropriate leadership style. In this paper the results of mixed-method data collection approach at a components facility of a German commercial vehicle manufacturer indicate that the Lean Leadership approach, which has proven to be very supportive in series production, can be also beneficial to meet the special requirements of the socio-technical production system ramp-up phase. Strong focus on Coaching/Qualification and/or Participation as well as the consideration of leadership guidelines, such as "Inform yourself and others", have been identified to be very helpful. Based on the findings in this paper, future research work in the field of production system ramp-up should not only concentrate on technical aspects, but on the joint optimization of sociotechnical production ramp-up systems. Therefore, the application of human-oriented concepts, tools and methods, such as an appropriate leadership style, is just as important as the application of organizational aspects or technologies in order to increase resilient behavior of production system ramp-up phase. The development of an approach that allows to purposively adopt existing LL principles and guidelines (that focus on series production so far) as well as the prioritization of principles that are of special importance in different phases of the production system lifecycle (e.g. in the production ramp-up phase) can be a valuable contribution to better manage production ramp-up projects in the future.

\section{References}

1. Dyckhoff H (1994) Betriebliche Produktion: Theoretische Grundlagen einer umweltorientierten Produktionswirtschaft, Zweite, verbesserte Auflage. Springer-Lehrbuch. Springer, Berlin, Heidelberg

2. Basse I., Schmitt S., Gartzen T., Schmitt R. (2014) Solution Principles for Managing Instabilities in Ramp-Up, 2nd International Conference on Ramp-Up Management 2014 (ICRM), Procedia CIRP 20 (2014) 93 -97

3. Laick T (2003) Hochlaufmanagement: Sicherer Produktionshochlauf durch zielorientierte Gestaltung und Lenkung des Produktionsprozesssystems. Dissertation, Universität Kaiserslautern

4. DIN Deutsches Institut für Normung e.V. (2009) Projektmanagement: Netzplantechnik: Beschreibung und Begriffe(69900:2009) 
5. DIN Deutsches Institut für Normung e.V. (2009) Projektmanagement: Projektmanagementsysteme: Teil 5: Begriffe (69901-5:2009)

6. Kuhn A, Wiendahl H-P, Eversheim W et al. (2002) Fast ramp up: Schneller Produktionsanlauf von Serienprodukten. Verl. Praxiswissen, Dortmund

7. Hanke T (2015) Lean Ramp-up: Ein Organisationsmodell für das Anlaufmanagement. Zugl.: Braunschweig, Techn., Univ., Diss., 2015. Schriftenreihe des IFU, vol 26. Shaker, Aachen

8. Wangenheim S. v. (1998) Planung und Steuerung des Serienanlaufs komplexer Produkte: Dargestellt am Beispiel der Automobilindustrie. Zugl.: Stuttgart, Univ., Diss., 1998. Europäische Hochschulschriften Reihe 5, Volks- und Betriebswirtschaft, vol 2385. Lang, Frankfurt am Main

9. Lanza G (2005) Simulationsbasierte Anlaufunterstützung auf Basis von Qualitätsfähigkeiten von Produktionsprozessen. Dissertation, Universität Karlsruhe

10. Risse J (2003) Time-to-Market-Management in der Automobilindustrie: Ein Gestaltungsrahmen für ein logistikorientiertes Anlaufmanagement. Zugl.: Berlin, Techn. Univ., Diss., 2002. Schriftenreihe Logistik der Kühne-Stiftung, vol 4. Haupt, Bern

11. Klocke F, Letmathe P, Stauder J et al. (2016) Anlauf soziotechnischer Produktionssysteme: Anlauforientierte Gestaltung mit ereignisorientierter Simulation. wt Werkstatttechnik online 106(6): 451-456

12. Surbier, L., Alpan, G., Blanco, E., (2014) A Comparative Study on Production Ramp-up: State-of-the-art and New Challenges. Production Planning \& Control, 25/15: 1264-1286.

13. Preuss S, Krämer B, Steinborn A et al. (2007) Effizientes Anlaufmanagement innerhalb KMU-basierter Kunden-Lieferanten-Beziehungen - Betriebliche Umsetzung und Evaluation -. Bochumer Berichte zur Angewandten Psychologie $(23 / 06)$

14. Sydow J (1985) Der soziotechnische Ansatz der Arbeits- und Organisationsgestaltung: Darstellung, Kritik, Weiterentwicklung. Campus Forschung, vol 428. Campus-Verlag, Frankfurt/Main

15. Heine, I., Beaujean, P., Schmitt, R. (2016) Improving Production Ramp-up through Human Resource Methods. Quality Management Journal, 23/1: 7-19.

16. Dombrowski U, Mielke T (2014) Lean Leadership - 15 Rules for a Sustainable Lean Implementation. Procedia CIRP 17: 565-570. doi: 10.1016/j.procir.2014.01.146

17. VDI Verein Deutscher Ingenieure (2017) Ganzheitliche Produktionssysteme Führung 03.100.30 (2871 Blatt 1). Accessed 06 Mar 2019

18. Creswell, J.W., Clark, V.L., 2011, Designing and Conducting Mixed Methods Research. 2nd Edition SAGE Publishing. 